\title{
Etiologia da Podridão do Coleto de Brachiaria brizantha em Pastagens da Amazônia
}

\author{
Maria de Lourdes R. Duarte ${ }^{1}$, Fernando C. Albuquerque ${ }^{1}$, Rosa Maria V. Sanhueza ${ }^{2}$, \\ Jaqueline R. Verzignassi ${ }^{1}$ \& Norio Kondo ${ }^{3}$
}

${ }^{1}$ Embrapa Amazônia Oriental, Cx. Postal 48, CEP 66095-100, Belém, PA, Brasil, e-mail: mlourdes@cpatu.embrapa.br; ${ }^{2}$ Embrapa Uva e Vinho, Cx. Postal 30, CEP 95700-000, Bento Gonçalves, RS, Brasil, e-mail: rosa@cnpuv.embrapa.br;

${ }^{3}$ Graduate School of Agriculture, Hokkaido University, Kita 9, Nishi 9, Kita-ku, Sapporo 060-0809, Japan, e-mail: norikon@res.agr.hokudai.ac.jp

Autor para correspondência: Maria de Lourdes Reis Duarte

DUARTE, M.L.R., ALBUQUERQUE, F.C., SANHUEZA, R.M.V.; VERZIGNASSI, J.R. \& KONDO, N. Etiologia da podridão do coleto de Brachiaria brizantha em pastagens da Amazônia. Fitopatologia Brasileira 32:261-265. 2007.

\section{RESUMO}

Desde 1995, pastos formados com Brachiaria brizantha cv. Marandu vêm sendo devastados por uma doença cujo sintoma típico é a morte de touceiras. Das amostras de plantas coletadas nos municípios de Paragominas (PA), Carutapera (MA) e Araguaína (TO), exibindo sintomas iniciais da doença, bem como, de sementes obteve-se quatro isolados de Pythium spp. e um de Rhizoctonia solani associados aos tecidos doentes. Os resultados dos testes de patogenicidade comprovaram que o principal agente da podridão do coleto do capim-braquiarão é Pythium periilum. A infestação do solo com mistura de inóculo dos três isolados de $P$. periilum e de $R$. solani resultou em elevada quantidade de doença ( $<0,01)$. Na presença de alta população de $R$. solani, no solo, a associação desses patógenos deverá aumentar as áreas degradadas de pasto de capimbraquiarão, principalmente aquelas manejadas de modo inadequado, desde que $R$. solani é um reconhecido patógeno de $B$. brizantha. Trata-se do primeiro registro de $P$. periilum como agente primário de doença, em coleto de $B$. brizantha.

Palavras-chave adicionais: doenças de gramíneas, Pythium periilum, Rhizoctonia solani, registro de nova doença.

\begin{abstract}
Etiology of collar rot of Brachiaria brizantha cv. Marandu in Amazonian pastures

Amazonian pastures formed with Brachiaria brizantha Marandu cultivar (also known as 'Braquiarão') have been devastated by a new disease since 1995, whose typical symptoms are diseased plants dispersed in pastures. Four Pythium and one Rhizoctonia isolates were recovered from plants in the early stages of infection and infected seeds,. The results of the pathogenic tests showed P. periilum as the main pathogen. Inoculations of healthy plants with the pathogen alone or in mixture resulted in a high rate of disease $(\mathrm{p}<0.01)$ when $P$. periilum and $R$. solani were present in 'Braquiarão' plant tissues, showing that both pathogens are associated. This is the first report of $P$. periilum as the primary agent of collar rot on $B$. brizantha.
\end{abstract}

Additional keywords: grass disease, Pythium periilum, Rhizoctonia solani, new disease report, palisade grass.

Apesar da grande diversidade de gramíneas ocorrentes na região tropical úmida, ainda não foi encontrada, na Amazônia, uma gramínea nativa que reuna as características desejáveis de palatabilidade, de proteínas e de sólidos totais, que possa ser usada na formação de pastagem cultivada. As pastagens cultivadas, antes restritas a pequenas áreas da fazenda, competem hoje com as culturas por fertilizantes e tecnologias, exigindo cultivares melhoradas, o que justifica o investimento em programas de seleção e de melhoramento genético (Valle et al., 2004)

Várias espécies pertencentes aos gêneros Brachiaria, Andropogon e Panicum foram testadas e, posteriormente, substituídas por outras gramíneas. Uma das últimas gramíneas introduzidas, a Brachiaria humidicola (Rendle) Schweick., conhecida como quicuio da Amazônia, espécie promissora para cultivo, principalmente em solos argilosos e muito úmidos, teve de ser substituída gradualmente, por Brachiaria brizantha (A. Rich.) Stapf cv. Marandu devido à alta suscetibilidade à cigarrinha das pastagens (Deois incompleta Walker).

Aárea cultivada com pastagem no Brasil duplicou nos últimos 20 anos, atingindo 100 milhões de hectares, devido ao uso de Brachiaria spp. e Panicum spp. (Valle et al., 2004). Estima-se que, desses 100 milhões, 60 milhões de hectares sejam cultivados com $B$, brizantha cultivar Marandu, os quais alimentam $40 \%$ do rebanho nacional (Teixeira Neto et al., 2000). Contribuíram para o sucesso do Braquiarão, a alta disponibilidade e qualidade das sementes, a rapidez no estabelecimento, a boa produtividade, a persistência e a alta capacidade de competição com plantas invasoras entre as quais Vismia guianensis Seem., Ipomoea asarifolia Roem. \& Schult., Solanum spp., Lantana camara L., Imperata brasiliensis Trin., Paspalum virgatum L. e Andropogon bicornis L.

Além de manchas foliares causadas por Drechslera incurvata (C. Bernard) M.B. Ellis e Bipolaris cynodontis 
(Marignoni) Shoemaker e ferrugem [Puccinia levis var. panici-sanguinalis (Rangel) Ramachar \& Cummins] a maioria dos patógenos registrados no capim-braquiarão estão associados a sementes (Mendes et al., 1998; Verzignassi \& Fernandes, 2006).

Após 15 anos de cultivo, touceiras de capimbraquiarão começaram a exibir sintomas de amarelecimento seguido de morte, em pastos localizados nos estados do Pará, Acre, Maranhão, Rondônia e ultimamente, em Tocantins. A morte do capim-braquiarão tem sido alvo de atenção por parte de pesquisadores da Embrapa, o que justificou várias viagens visando a diagnose do problema (Souza et al., 1999; Valerio et al., 2000). Com base nas observações efetuadas durante as viagens, foi constatado que o problema apresentava causa complexa, estando associado a processos progressivos de degradação ambiental e das pastagens em função do uso contínuo sem manutenção adequada das áreas. Estresse hídrico na estação seca ou excesso de umidade e predisposição ao ataque de fungos de raízes nessas condições, bem como altas populações de cigarrinhas, principalmente do gênero Mahanarva, e o monocultivo de B. brizantha, também foram citados como possíveis causas.

Como recomendações, os documentos apontam para a sustentabilidade do sistema produtivo, por meio da diversificação de forrageiras; repovoamento de áreas demasiadamente desmatadas para abrigo de parasitas e predadores de insetos (reguladores populacionais); manejo adequado das pastagens, de modo a evitar altura inferior a $40 \mathrm{~cm}$ durante o período de proliferação das pragas locais, utilizando-se pastejo rotacionado e efetuando a correção da fertilidade do solo, para assegurar maior vigor das plantas; e a restrição ao máximo, do uso do fogo e de pesticidas.

No presente trabalho são apresentados os resultados obtidos nos estudos sobre a etiologia da doença, meios de transmissão do patógeno, bem como, sugestões de estratégias de controle para conter o avanço da doença para novas áreas.

Isolados de Pythium spp. e de Rhizoctonia solani J.G. Kühn foram obtidos de touceiras de capim-braquiarão (Brachiaria brizantha) com sintomas iniciais de podridão do coleto, coletadas nas fazendas Pequiá e Roseta, em Paragominas PA; na fazenda Canabrava, em Carutapera MA; e em Araguaína TO entre março de 2000 e junho de 2002, durante a estação chuvosa, quando a doença é mais severa. Uma amostra de sementes oriunda de Mato Grosso do Sul, foi utilizada para estudos de transmissão dos patógenos por sementes. As amostras de plantas foram lavadas em água corrente e usadas para descrever os sintomas e proceder ao isolamento de fungos patogênicos. Após a lavagem, plantas individuais foram separadas e secas em toalhas de papel absorvente antes de serem submetidas ao isolamento em placas de Petri contendo $20 \mathrm{~mL}$ de agar-água a 1,5\%. Após a incubação por cinco dias sob regime de $12 \mathrm{~h}$ luz/12 h escuro, à temperatura de $25{ }^{\circ} \mathrm{C}$, as placas foram examinadas para verificação da presença de Pythium spp. Pontas de hifas de isolados potenciais foram transferidas para tubos de ensaio contendo cenoura-ágar (CA). Culturas de trabalho foram mantidas em tubos contendo batata-dextrose-ágar (BDA) ou CA e, culturas-estoque foram preservadas em frascos contendo água destilada esterilizada e mantidas a $\pm 5{ }^{\circ} \mathrm{C}$ (Benedek, 1962). Foi usado o mesmo procedimento para obtenção e manutenção do isolado de $R$. solani.

A produção de esporângios, anterídios, oogônios e oósporos foi induzida de dois modos. Primeiro, blocos de ágar contendo micélio dos fungos isolados foram transferidos para tubos de ensaios contendo meio CA e incubados sob luz difusa à temperatura ambiente. No segundo modo, foi usada uma modificação da técnica de Emerson (1958). Blocos de farinha de milho-ágar (FMA) com micélio de todos os isolados foram transferidos para placas de Petri contendo o meio ágar-água a 1,5\%. Cinco pedaços de folhas de Agrostis stolonifera L. com $2 \mathrm{~cm}$ de comprimento, foram esterilizados em autoclave, colocados na superfície do meio, distantes cerca de $1,5 \mathrm{~cm}$ do bloco de cultura e incubados sob luz difusa, a $25{ }^{\circ} \mathrm{C} \pm 1{ }^{\circ} \mathrm{C}$. Após a completa colonização das folhas pelos isolados de Pythium spp., os cinco segmentos de folhas por placa e por isolado foram transferidos para placas de Petri de $4 \mathrm{~cm}$ de diâmetro contendo água de chuva e água destilada esterilizadas, na proporção de 1:1 (v/v) e incubadas à $20^{\circ} \mathrm{C}$ e $25^{\circ} \mathrm{C}$. Após 48 horas, as placas contendo os quatro isolados de Pythium (Pythium 0, I, II e III) foram examinadas sob microscópio estereoscópio para observação de órgãos sexuais e assexuais formados sobre as folhas. Como o isolado Pythium I apresentou crescimento lento quando comparado aos outros isolados do fungo, a transferência dos blocos de cultura para placas contendo folhas de grama só ocorreu após 96 horas. Após cada observação, a água das placas foi trocada diariamente, por três dias. $\mathrm{O}$ meios de cultura batata-cenoura-ágar (BCA), V-8 e farinha-de-milho ágar (FMA) foram usados para comparar a morfologia das colônias (Tuite, 1969). Os estudos morfológicos foram realizados no Laboratório de Fitopatologia da Faculty of Science, Hokkaido University, Sapporo, Japan.

As espécies de Pythium foram identificadas pela chave e descrição de van der Plaats-Niterink (1981). A identificação foi baseada nas observações das estruturas sexual e assexual, tamanho das estruturas reprodutivas e morfologia da colônia (Domsch et al., 1980; van der PlaatsNiterink, 1981).

Quirera de milho (milho triturado) foi passada em peneira 10 mesh para uniformização das partículas. Cerca de $100 \mathrm{~g}$ da quirera foi colocado em cada erlenmeyers de 500 $\mathrm{mL}$ e umedecido com $50 \mathrm{~mL}$ de água destilada. O substrato foi autoclavado por 30 minutos, duas vezes. Blocos de cultura dos fungos foram transferidos para placas contendo CA (Pythium spp.) e BDA ( $R$. solani) e incubadas a $25^{\circ} \mathrm{C}$ $\pm 1{ }^{\circ} \mathrm{C}$, sob condições controladas. Após três dias, um disco de $10 \mathrm{~mm}$ de diâmetro retirado da periferia das colônias foi transferido para cada um dos frascos contendo quirera, os quais foram incubados sob as mesmas condições até que os fungos colonizassem todo o substrato (Sanhueza et al., 1984). Vasos de $450 \mathrm{~mL}$ de capacidade foram cheios com uma 
camada de $150 \mathrm{~mL}$ de solo esterilizado a vapor úmido, uma camada de $37,5 \mathrm{~mL}$ de inóculo distribuído de modo a formar uma camada de $1 \mathrm{~cm}$ de espessura, a qual foi recoberta com outra camada de $300 \mathrm{~mL}$ de solo esterilizado. Sementes foram peneiradas para eliminação do terriço e lavadas em água corrente antes da semeadura. Foram semeadas 270 sementes, por vaso. Os vasos permaneceram no interior da casa telada até as plantas atingirem $15 \mathrm{~cm}$ de altura. Em seguida, foram transferidos para a área externa da casa telada a fim de ficarem sujeitos a intempéries (sol, chuva, umidade, alta temperatura). Os tratamentos consistiram de vasos infestados com os patógenos, isoladamente ou em mistura no seguinte esquema: T1 $=$ Pythium $\mathrm{I} ; \mathrm{T} 2=$ Pythium II; T3 = Pythium III; T4 = T1 $+\mathrm{T} 2 ; \mathrm{T} 5=\mathrm{T} 1+$ $\mathrm{T} 3 ; \mathrm{T} 6=\mathrm{T} 2+\mathrm{T} 3 ; \mathrm{T} 7=\mathrm{T} 1+\mathrm{T} 2+\mathrm{T} 3 ; \mathrm{T} 8=\mathrm{T} 1+\mathrm{T} 2+\mathrm{T} 3$ + Rhizoctonia solani $; \mathrm{T} 9=R$. solan $;$, $\mathrm{T} 10=$ Testemunha (quirera de milho esterilizada, em solo esterilizado). A patogenicidade dos isolados foi avaliada 24 dias após a semeadura, pela contagem do número de plantas mortas por repetição, por tratamento. $\mathrm{O}$ experimento foi instalado em delineamento experimental inteiramente casualizado com 10 tratamentos e três repetições, cada vaso representando uma parcela. Os dados foram transformados em arco seno $(x+0,5)^{1 / 2}$, submetidos a analise da variância e as médias comparadas pelo teste de Tukey, em nível de $5 \%$ de significância $(\alpha=0,05)$.

Um ensaio preliminar foi conduzido a fim de verificar a possível transmissão de patógenos pela semente. Para tanto, sementes de capim-braquiarão foram peneiradas para eliminação do terriço. Uma amostra de $200 \mathrm{~g}$ de sementes foi separada e dividida em duas subamostras de $100 \mathrm{~g}$. A primeira sub-amostra foi tratada com o fungicida thiran na formulação pó seco na dose de $475 \mathrm{~g}$ de i.a./100 kg de sementes, servindo a outra sub-amostra de testemunha. Após a semeadura, as plantas permaneceram na casa telada até atingir a altura de $15 \mathrm{~cm}$, quando então foram transferidas para o ambiente externo da casa telada onde ficaram submetidas à ação do ambiente. $\mathrm{O}$ efeito do tratamento foi avaliado considerando-se a incidência da doença.

As pastagens afetadas apresentaram touceiras exibindo amarelecimento das folhas mais externas. Esse amarelecimento iniciava-se a partir do ápice em direção às bordas, formando um $\mathrm{V}$ com o vértice voltado para a extremidade da folha. Com o progresso da doença, o amarelecimento atingia a base das folhas e bainhas, resultando no secamento total da folha (Figura 1A). A doença progredia para as folhas mais internas até que todo o perfilho tornava-se seco. $\mathrm{Na}$ base da touceira, o colmo apresentava podridão úmida que avançava até $15 \mathrm{~cm}$ acima do solo. A região apodrecida apresentava-se deprimida e com a margem irregular na região de transição entre a parte sadia e a afetada. Antes das folhas ficarem amarelas, em alguns casos, surgiram manchas úmidas arredondadas com bordas irregulares e de coloração escura. Na região do coleto, os internódios apresentavam-se apodrecidos, sendo invadidos pela bactéria Erwinia carotovora (Jones) Holland, que causa podridão-mole da medula, exalando odor fétido. Fazendo-se um corte longitudinal no colmo observava-se descoloração vascular e destruição da medula dos internódios. As raízes não foram afetadas pelo patógeno, por isso comumente encontrou-se novos perfilhos entre os colmos infectados, mas, que posteriormente tornaram-se apodrecidos. Quando todos os perfilhos eram afetados a touceira secava completamente assemelhando-se aos sintomas de morte em reboleira.

Dos tecidos infectados foram obtidos quatro isolados de Pythium identificados como Pythium 0. (coleto), Pythium I (coleto), Pythium II (sementes) e Pythium III (coleto) e apenas um isolado de Rhizoctonia solani (bainha das folhas). Esses isolados foram identificados como Pythium periilum Drechsler com base nas características

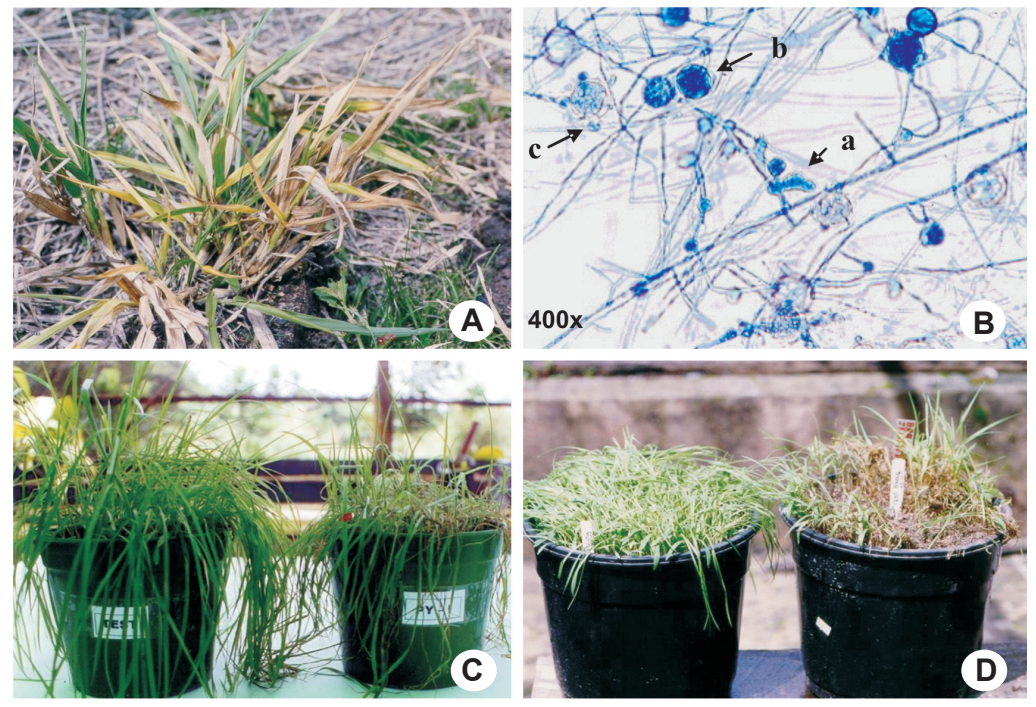

FIG. 1 - Podridão do coleto de Brachiaria brizantha cv. Marandu (capim-braquiarão). A. Touceiras com sintomas iniciais de podridão do coleto; B. Esporângio (a), oogônio (b) e oosporo (c) de Pythium periilum produzidos em folhas de Agrostis stolonifera $(400 \mathrm{x}) ;$ C. Plantas inoculadas com Pythium periilum (direita) ao lado de plantas não inoculadas; D. Plantas oriundas de sementes tratadas com thiran (esquerda) ao lado de plantas Testemunha. 
morfológicas e fisiológicas (van der Plaats-Niterink, 1981). A espécie apresentou micélio asseptado, medindo $2,2 \mu \mathrm{m}$ de largura. Os septos só foram observados próximos dos órgãos reprodutivos. Em meio $\mathrm{BCA}$ produziu micélio imerso e a colônia apresentou a aparência radiada, quando observada pelo lado inferior das placas de Petri. Em meio CA produziu abundantes oogônios e anterídios. Os oogônios eram globosos, de parede lisa e espessa medindo $15 \mu \mathrm{m}-$ $17 \mu \mathrm{m} \times 22 \mu \mathrm{m}-26 \mu \mathrm{m}$. Os anterídios encontrados foram monoclinos e diclinos, em número de 2 a 5 , fertilizando um único oogônio. Os oósporos globosos, de parede lisa, mediram $1 \mu \mathrm{m}$ a $2 \mu \mathrm{m}$ de espessura, pleróticos ou quase pleróticos.

Folhas de gramíneas colonizadas, 48 horas após a imersão em água, produziram abundantes zoosporângios formados de parte filamentosa medindo $1 \mu \mathrm{m}$ de largura e parte de elementos inflados (Figura 1B). Os elementos inflados mediram 7,5 $\mu \mathrm{m}-16,0 \mu \mathrm{m}$ x 20,0 $\mu \mathrm{m}-46,2 \mu \mathrm{m}$. Todos os isolados produziram zoosporângios e oósporos a $20^{\circ} \mathrm{C}$. Á temperatura de $25^{\circ} \mathrm{C}$, todos os isolados produziram oósporos, mas apenas o isolado Pythium III produziu zoosporângios. Não foi observada a liberação de zoósporos a $25^{\circ} \mathrm{C}$. Os isolados foram capazes de crescer até a temperatura de 40 ${ }^{\circ} \mathrm{C}$, sendo esta uma característica de $P$. periilum. Todos os isolados apresentaram habilidade em infectar os tecidos do coleto de $B$. brizantha, quando inoculados isoladamente ou associados (Tabela 1).

As primeiras plantas exibindo sintomas de secamento das folhas seguido de morte de mudas foram observadas 24 dias após a semeadura, em solo pré-infestado com Rhizoctonia solani, alcançando valor de incidência de $\quad 60,7 \%$ e com inóculo composto dos três isolados de Pythium associados a $R$. solani com valor $49,5 \%$ (Tabela 1 ). Com o progresso

TABELA 1 - Incidência de podridão do coleto em mudas de capimbraquiarão, em solo pré-infestado com três isolados de Pythium periilum e Rhizoctonia solani isoladamente e combinados entre si

\begin{tabular}{lc}
\hline \hline Tratam entos & ${ }^{1}$ Incidência de doença (\%) \\
\hline Pythium -I & $49,54 \mathrm{a} \mathrm{a}^{2}$ \\
Pythium -II & $36,52 \mathrm{ab}$ \\
Pythium III & $49,43 \mathrm{a}$ \\
Pythium I + Pythium II & $52,57 \mathrm{a}$ \\
Pythium I + Pythium III & $61,05 \mathrm{a}$ \\
Pythium II + Pythium III & $56,25 \mathrm{a}$ \\
Pythium I + Pythium II + & $49,56 \mathrm{a}$ \\
Pythium III & \\
Pythium I + Pythium II + & $49,47 \mathrm{a}$ \\
Pythium III + Rhizoctonia solani & \\
Rhizoctonia solani & $60,67 \mathrm{a}$ \\
Testemunha & $13,90 \mathrm{~b}$ \\
CV\% & 9,94 \\
\hline
\end{tabular}

${ }^{1}$ Média de 3 repetições. Médias seguidas de mesma letra não diferem entre si, pelo teste de Tukey, em nível de 5\% de significância $(p<0,01) .{ }^{2}$ Dados originais. Para análise da variância, os dados foram transformados em arc sen $(\mathrm{x}+0,5)^{1 / 2}$. da doença, os sintomas de amarelecimento das folhas seguido de morte das plantas foram surgindo nas plantas inoculadas (Figura 1C). A incidência da doença variou de $36,5 \%$ (Pythium II) a 61,05\% (Pythium I + Pythium III). A infestação do solo com inóculo combinado de $P$. periilum e $R$. solani resultou em elevado índice de doença e, aos 53 dias, todas as plantas inoculadas de todos os tratamentos tinham morrido. Na presença de alto nível de inóculo, a associação desses patógenos deverá aumentar o nível de degradação das pastagens, principalmente naquelas manejadas de modo inadequado, como apontado por Teixeira Neto et al. (2000).

Sementes tratadas com o fungicida thiram originaram plantas sadias. Nas plantas testemunha, os sintomas só se tornaram evidentes quando as plantas ficaram sob a ação do ambiente, o que demonstra que houve necessidade de excesso de umidade para que a doença se manifestasse. A incidência de doença nas plantas oriundas de sementes não tratadas $(13,9 \%)$ indicou que o patógeno pode ser transmitido pela semente. (Figura 1D).

As características morfológicas e fisiológicas, bem como os resultados dos testes de patogenicidade, comprovaram que a espécie de fungo associada à podridão do coleto de $B$. brizantha $\mathrm{cv}$. Marandu foi Pythium periilum. Embora $R$. solani tenha sido isolado da bainha da folha de plantas doentes, a freqüência de isolamento foi relativamente baixa. Apenas $20 \%$ dos isolados correspondiam a $R$. solani, evidenciando a ação primária de $P$. periilum no apodrecimento do coleto de plantas de capim-braquiarão.

Por causa da grande sensibilidade a antagonistas e outras influências ambientais, as espécies de Pythium usualmente não causam tanto dano como a sua densidade no solo pode sugerir (Domsch et al., 1980). Nos últimos 10 anos, apenas Pereira et al. (1998) relataram uma espécie de Pythium sp. afetando introduções de Brachiaria spp. sob condições de alta umidade do solo na Costa Rica, sem, no entanto, identificar a espécie de Pythium envolvida. Não há registro na literatura da incidência de $P$. periilum infectando espécies do gênero Brachiaria spp. Um dos primeiros relatos de $P$. periilum refere-se à associação do patógeno a raízes de cana-de-açúcar (Teakle, 1960), na Austrália. Posteriormente, van der Plaats-Niterink (1981) também registrou a ocorrência de $P$. periilum como um parasita fraco associado a raízes de cana-de-açúcar. A despeito de o patógeno ter sido relatado associado a raízes (Teakle, 1960), no capim-braquiarão, P. periilum afetou principalmente o coleto, não tendo sido observadas plantas com podridão radicular.

Com base na freqüência de isolamento e no grau de severidade sobre Brachiaria brizantha cultivar Marandu, conclui-se que $P$. periilum é o principal agente patogênico envolvido na podridão do coleto do capim-braquiarão nas pastagens da Amazônia Oriental. Trata-se do primeiro relato de $P$. periilum como agente primário de doença, em coleto de B. brizantha. 


\section{REFERÊNCIAS}

BENEDEK, T. Fragmenta mycologia. II. On Castellani's "Water Cultures" and Benedek's "Mycotheca" in Chloralactophenol. Mycopathologia et Mycologia Applicata 17:255-260. 1962.

DOMSCH, K.H., GAMS, W. \& ANDERSON, T.H. Compendium of soil fungi. Vol. 1. London. Academic Press. 1980.

EMERSON, R. Mycological organization. Mycologia 50:453-487. 1958.

MENDES, M.A.S., SILVA, V.L., DIAANESE, J.C., FERREIRA, M.A.S.V., SANTOS, C.E.N., GOMES NETO, E., URBEN, A.F. \& CASTRO, C. (Eds.) Fungos do Brasil. Brasília. Embrapa-SPS/ Embrapa-Cenargen. 1988.

PEREIRA, C.Z., GONZALEZ, Q.R., BUSTAMANTE, E. \& ARGEL, P. Influencia de la humedad del suelo sobre la susceptibilidad de Brachiaria a hongos patogenos. Manejo Integrado de Plagas 49:51-57. 1998.

SANHUEZA, R.M.V., BALMER, E. \& MILANEZ, A.I. Patogenicidade de Pythium arrhenomanes Drechsler do complexo Pythium acanthicum - P. oligandrum "Sensu" Watanabe, em cultivares de cana-de-açúcar. Summa Phytopathologica 10:206215. 1984.

SOUZA, O.C., VALLE, L.C.S., ZIMMER, A.H. \& KOLLER, W.W. Diagnóstico de morte de pastagens de Brachiaria brizantha nas regiões de Araguaína, TO e Redenção, PA. Campo Grande: Embrapa Gado de Corte, 1999. (Embrapa Gado de Corte. Documentos, 96). Disponível em http://www.cnpgc.embrapa.br/ publicacoes/doc/doc96/index.html. Acesso em 15 jan. 2007.

TEAKLE, D.S. Species of Pythium in Queensland. Queensland Journal of Agricultural Science 17:15-31. 1960.

TEIXEIRA NETO, J.F., SIMÃO NETO, M., COUTO, W.S., DIAS-FILHO, M.B., SILVA, A.B., DUARTE, M.L.R. \& ALBUQUERQUE, F.C. Prováveis causas da morte do capimbraquiarão (Brachiaria brizantha cv. Marandu) na Amazônia Oriental (Relatório Técnico). Belém PA. Embrapa Amazônia Oriental. 2000. (Documentos, 36)

TUITE, J. Plant Pathological Methods. Fungi and Bacteria. Minneapolis MN. Burgess Publishing. 1969.

VALLE, C.B., JANK, L., RESENDE, R.M.S. \& BONATO, A.L.V. Tropical forage breeding in Embrapa: current situation and prospects. Working Reporter. Japan International Researcher Center for Agricultural Sciences 36:61-65. 2004.

VALÉRIO, J.R., SOUZA, O.C., VIEIRA, J.M. \& CORRÊA, E.S. Diagnóstico de morte de pastagens nas regiões central e norte do Estado de Mato Grosso. Campo Grande: Embrapa Gado de Corte, 2000. (Embrapa Gado de Corte. Documentos, 98). Disponível em http://www.cnpgc.embrapa.br/publicacoes/doc/doc_pdf/DOC098. pdf. Acesso em 15 jan. 2007.

VAN DER PLAATS-NITERINK, A.J. Monograph of the Genus Pythium. Studies in Mycology 21. 1981.

VERZIGNASSI, J.R. \& FERNANDES, C.D. Doenças em Forrageiras. Campo Grande MT. Embrapa Gado de Corte. Documento 50. 2001. Disponível em http://www.cnpgc.embrapa.br/publicacoes/divulga/ divulga_pdf/gdcd50PeB.pdf. Acesso em 15 jan. 2007. 